\title{
Design Support Based onto Knowledge to Increase Product Reliability and Allow Optimized Abacus Development
}

\author{
Jérémy Boxberger ${ }^{1,2}$, Daniel Schlegel ${ }^{2}$, Nahdir Lebaal ${ }^{2}$, and Samuel Gomes ${ }^{2}$ \\ ${ }^{1}$ Zurfluh-Feller, 45 Grande Rue, 25150 Autechaux-Roide \\ ${ }^{2}$ Laboratoire M3M, UTBM, 90010 Belfort Cedex
}

\begin{abstract}
High competition and low manufacturing costs in emerging countries, force European firms to improve quality, cost and delivery. Research and development departments have to look towards high production design methods and tools in order to stay competitive. Our research allow to reduce routine design process and thereby increase time for added value design tasks, particularly innovative design activities. We have applied our methodology onto a roller shutter tube. Existing abacuses are used to define tube deformation, but these abacuses are too restrictive. Our case determine the input information and create a model using our method to create new abacuses more relevant. Our contribution uses the explicit knowledge embedded in a KBE application to cocreate or update parametric 3D models with its assembly environment. By implementing this method in an industrial company, we have reduced routine design tasks and improved the robustness of the product design and the product assembly.
\end{abstract}

Keywords: Abacus, Robust design, Design for X, Knowledge Based Engineering, Product lifecycle management, Product data management, Optimization.

\section{Introduction}

The current industrial context forces companies to develop new concepts at ever increasing speed. Quality, cost and lead time are the relevant performance indicators for firms [1][2]. However, after having shifted manufacturing to low cost countries, to prevent the relocation of work dedicated to routine design, we must reduce the length of the non value-added tasks to free up time for innovative projects. Engineering design is a source of competitive advantage for manufacturing companies. Reducing the development time is a key factor in the successful completion of the product development process. During the last decades, the design process is subject to new methodologies and tools to make it more and more efficient. Like what was done in manufacturing, lean engineering techniques were introduced into the design process. The objective is to reduce the non-added value tasks of the design process. Design is an information intensive activity. Because of the complex information dependencies that exist between design tasks, we cannot perform the design process as a once-through procedure. Therefore, iterations are necessary to resolve design 
problems. These iterations are often seen as non-added value tasks. Understanding and controlling iterations can improve the design process, and reducing them would have positive effects for the product development cycle time [3]. The purpose of lean engineering is to introduce new methodologies helping the designer approach the ideal design solution as rapidly as possible. This paper is organized as follows: first, we relate our current research on reducing routine design time, especially Design for $\mathrm{X}$, knowledge capitalization, top down design and optimization. The second section deals with our methodology, including the parametric model, finite element and optimization loops. The main goals of our contribution will be explained in this part. The next section presents an industrial applied case, where we have applied our methodology to a shutter assembly. Today, in order to minimise loss of information, different departments in a firm work together around the product lifecycle (product lifecycle management: PLM) from the customer's needs, to the end of life [4][5] Thus, different approaches, called integrated design, parallel design or collaborative design have already been developed [6]. These methods have allowed us to deal with the knowledge domain earlier in the design process. In this context, the Design for X approach [7] (design for manufacture, design for assembly, design for quality, design for recycling etc...) has been introduced in order to reduce product lifecycle and also increase engineering productivity by reducing non value-added tasks. A large number of papers have been delivered over the last forty years about product design [8], with the resounding view that routine design occupies a large place in firms. Innovative design could be increased by reducing routine design and this could also release time for other tasks. Within Design for X, design for manufacturing and design for assembly have been the most discussed topics in the last thirty years. The knowledge available in the manufacturing process has to be known by the designers in order to speed up product design and find the best quality product faster. Swift describes some standard rules about DFM [9]. Using these rules as a base for KBE application, parametric models can be created and coupled with an optimization algorithm for problem resolution [10]. In addition to this, thanks to the development of CAD tools, different types of product design approach have appeared. The most used, called bottom-up design', consists in parts creation before assembly. At the opposite end, 'top down design' is a methodology that starts at the highest level of a design concept and proceeds towards the lowest level, starting with the broad project specification in mind and putting that information in a centralized location. The design progresses from this information to the individual parts. This makes it easy to design and manage large product assemblies. Changes made in a central location will propagate to all levels of the design. As a result, multiple designers can work on a project in parallel and communicate design data easily and quickly, with full confidence that all components will fit seamlessly into the final product. The same idea was applied with the integration of knowledge. On one hand, some studies have been done with bottom-up knowledge extraction [11][12] whilst others have focused on top-down knowledge extraction or knowledge lead by models. Some works show this kind of methodology, such as MKSM (Methodology for Knowledge System Management)[13], MASK (Méthode d'Acquisition et de Structuration des Connaissances) [14], CYGMA (CYcle de vie et Gestion des Métiers et Applications) [15], etc. Our objective is articulated around decision support and assembly configuration validation. A non-experienced user can lose time selecting the correct reference among a large number of references for the 
first time. In addition, he may choose the wrong reference or not the best one. Obtaining the optimum settings is often the result of tiresome trial and error corrections, during which time the various solutions are tested and modified. As a result, the settings are often non optimal and are just acceptable. Achieving the optimal design is time consuming and one of the highest material and manpower costs. However, in many processes and structural designs, in order to improve quality and reduce time, the combination of numerical simulation using the finite element method with numerical optimisation techniques cannot be avoided [16][17]. Our contribution will deal on a multi-objective optimization procedure, used to improve performance of an assembly design based on expert knowledge, simulation and optimized abacuses. Reducing non value-added tasks in this project domain improves productivity and quality of the product and the design process activities. The first issue is to keep the information usable for all users, and not only for experts. Another issue consists in defining how to preserve various knowledge typologies embedded in Project, Product and Process data and information management systems (PDM, PLM, MPM, etc.). The other relevant issue is to validate a new geometry definition for the product or a new combination of components. We have applied our methodology onto a roller shutter tube assembly in order to define a less restrictive abacus for the customer. Existing abacuses are used to define tube deformation according to the weight and the length, but these abacuses are too restrictive. Tests reveal, in some cases, that the abacus security level has a coefficient of 10 . The objective of our case was to determine the input information and create a model using our methodology in order to create new abacuses more representative of the reality. Our contribution uses the explicit knowledge embedded in a $\mathrm{KBE}$ application in order to co-create (or update) a parametric 3D model with its assembly environment. Then the application allows a new combination to be validated by the use of optimisation loops with a finite element tool. Decision support applications lead by knowledge will reduce routine design and will help a customer to check his system reliably using a parametric abacus. These parametric abacuses are created using optimization loops. They will replace existing standard abacuses which are too restrictive and in some cases obsolete. A last loop explained in our use case allows the parametric abacuses to be tested on extreme and worth value cases in real.

\section{Methodology}

The purpose of the following methodology is to facilitate routine design reduction. Routine design is present in all domains: from the project domain, to the product domain; our contribution will also deal with the process domain. Obviously, all are linked together. The first project domain is relative to the whole methodology used in the firm: from the customer needs to the final product and marketing. A standard methodology has been built taking into account the firm's history and modus operandi. [18] This methodology contains two different types of standard methods. According to the length and the complexity of the project, a short or long project-types is chosen by the direction. However, this method contains a large number of tasks, some are more relevant than others and some contain non-value added actions. We can also perform a microscopic analysis in a task to reveal routine subtasks which can be 
considered as value added. Many parts are often available in a large range of sizes within a family of parts. If a new assembly is modified, e.g. new geometry or new size of one or several features, the user has to select a new component, compatible with the new assembly, from within the same family. This method is based on the Design for manufacturing method and on knowledge-based engineering models that contain help for decision making while choosing the correct reference. Besides, the tool features automatic 3D model generation, including the part and the manufacturing tool together. The goal of the whole methodology is to allow extraction and knowledge re-use from the new models created. At the beginning, the experts input the rules related to their particular domain (equations, interactions, manufacturing tool settings, etc...) into a PLM tool. This information collection leads to the creation of the KBE application. The creation process of the KBE application depends on the particular case and on the manufacturing.

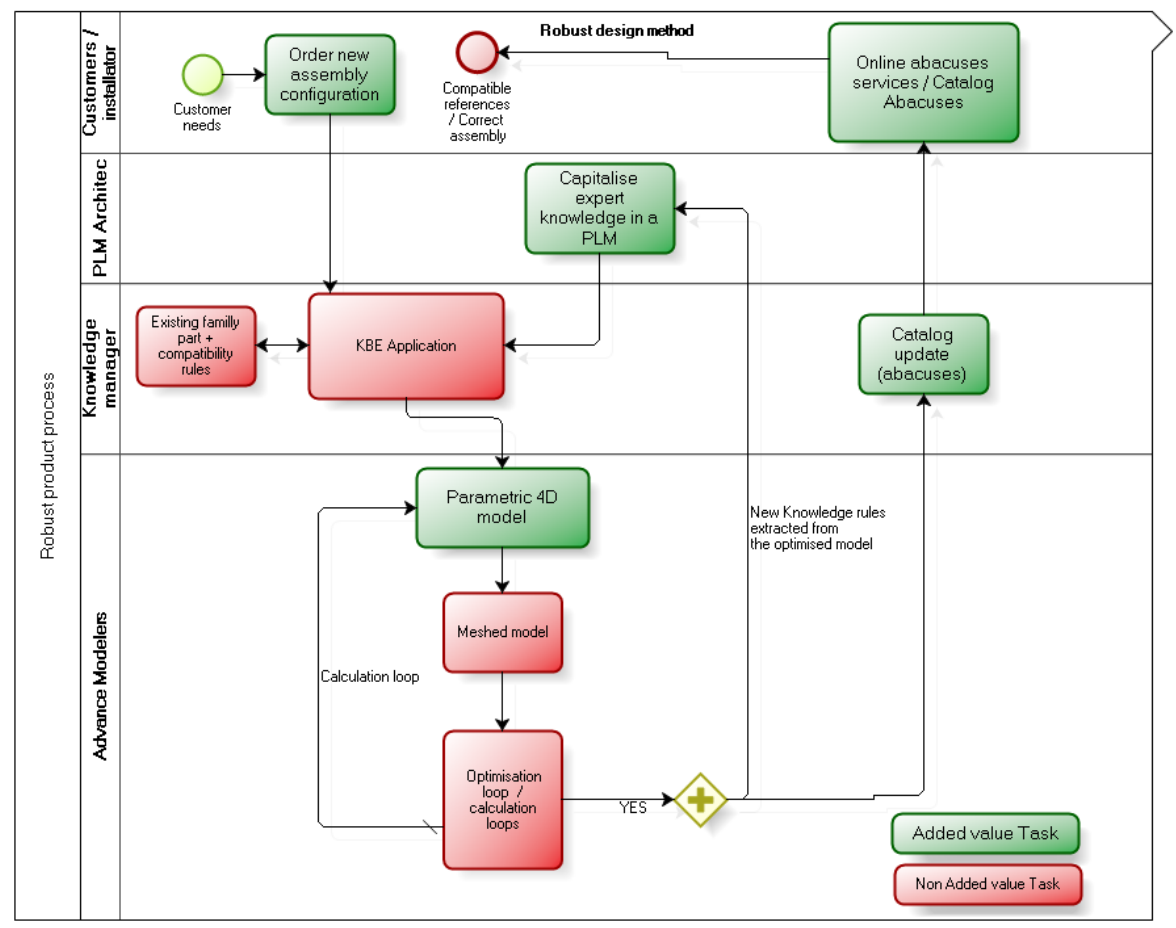

Fig. 1. Methodology represent by a BPMN Diagram

Our methodology is represented Fig.1 by a BPMN graph. It shows the methodology used and also the works currently tested and the results that we are expecting. The green tasks are added value tasks. There is added value when the actions performed can be used by the customers, for example, the CAD model can be used by the customer to visualise his assembly. On the other hand, the KBE model is only usable by the designer - it only allows time reduction for the designer. That's why the non value-added tasks must be performed in the minimum of time in order to meet the 
needs of customers faster. Then, by the connections established between the parametric model, the meshing tool and the optimization tool, loops can be performed in order to generate a large number of simulations to build precise curves. A last loop is performed between the optimized model and the PLM tool. This last loop contains information and knowledge according to the value stream defined and optimized in the first loops. This methodology allows a knowledge loop between the model, the PLM tool, the expert and the customer / installer to be created. This will lead to an increase of productivity and a knowledge record without any loss of information. The experts must validate the new knowledge implemented in the PLM knowledge base, but we can envisage experts not having to include this in the loop when the models are stabilized and reliable. In the next section, we will see that an additional real-time test was performed to check the reliability of the simulation model and the real model.

\section{Use Case}

\subsection{Context Application}

This methodology is used in an industrial firm that is specialized in shuttle components. The firm is a mid-range factory and has established a standard design method within the last few months. KBE applications are not used and parametric models are only just being deployed in the research and development office. A PLM tool is applied for Project-Product-Process functional and structural design, for the entire lifecycle and also for knowledge capitalization. This tool, called ACSP for « Atelier Collaboratif de Suivi de Projet » has been developed at Belfort-Montbéliard University of Technology, at the M3M laboratory. This PLM tool is specifically designed for adaptation to small firms, and is easily adapted to varying factory practices or history. Some work has already been done in the past on specification or on automatic project creation, which reduces routine time of project planning.

\subsection{Use Case Presentation}

The use case deals with a shutter tube. Today, the main objective for the installer is to select the best size of tube according to his assembly (shutter curtain weight, height, length, etc.). Existing abacuses can help the installer select his tube. The critical target parameter is the tube bend. In fact, when the shutter curtain is completely wound, the shutter risks to damaging the pelmet if the deformation is too high. However, tests reveal that the existing abacuses are too restrictive causing problems sometimes for the installer. These existing abacuses do not take account of the slat rigidity when the shutter is wound. However, the finite element calculations for the whole assembly (Fig. 2) take more than 10 hours. To address this, a simplified model was built with slats represented by squares which replicate the same quadratic movement as the slats. Using this geometry, the calculation was reduced to 10 minutes for 1 loop. 


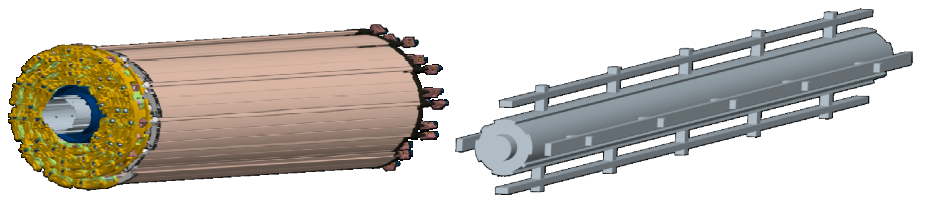

Fig. 2. Full assembly compared to simplified assembly

Our model uses as parameters, the length, the weight and the height of the shutter, the quadratic moment of the slat, the plug end length and the tube's dimension. The first parameter is the type of tube and its length. The type of fixation is selected according to the tube - only the size and the type can be changed. In addition the slat shape will modify the quadratic modulus, so this parameter is also needed. For the abacus the standard shape was used which represents $80 \%$ of the market. However, the KBE application allows this modulus to be changed.

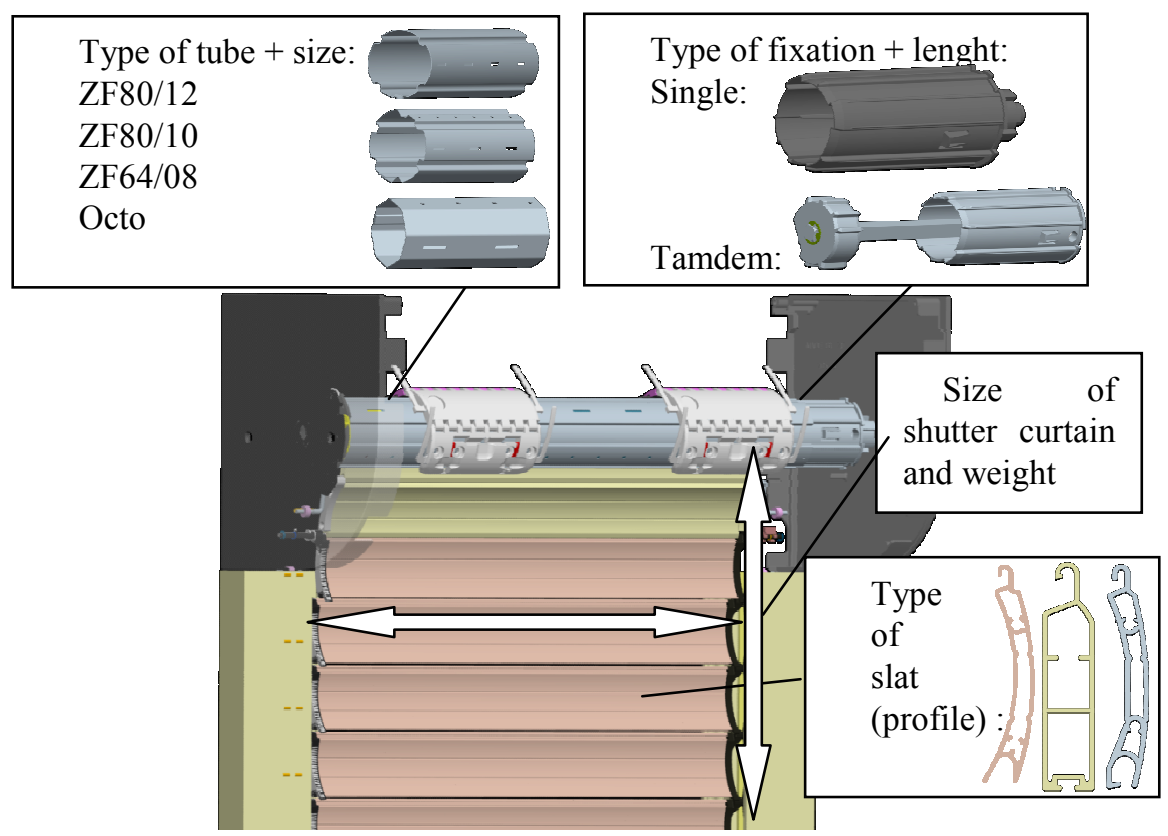

Fig. 3. Shutter configuration

The target is the deformation. The model is linked with a finite element tool and an optimisation tool which allows us to make loops between both modules.

\subsection{A KBE Modelling Method for Shutter Tube Components}

In order to create a $\mathrm{KBE}$ application we have to consider all of the parameters involved in the process and also all the knowledge embedded in the product. Knowing 
the important parameters will allow us to insert them into a PLM tool, thus allowing a $\mathrm{KBE}$ application extractor module, linked with a 3D commercial tool, to be generated.

\subsection{Results}

Six new abacuses were built, and validated with real testing on ten different sizes: 3 sizes for the 80/10 and the 64/08 and 4 for the 80/12 with different weights and tube lengths. In each case the difference in results between real and computer simulated has been a maximum of $1 \mathrm{~mm}$. Figure 4 compares the new abacuses with the shutter fully rolled and the old Abacuses. As these values were tested in real and validated by the expert, the new abacuses will be implemented in the next catalogue.

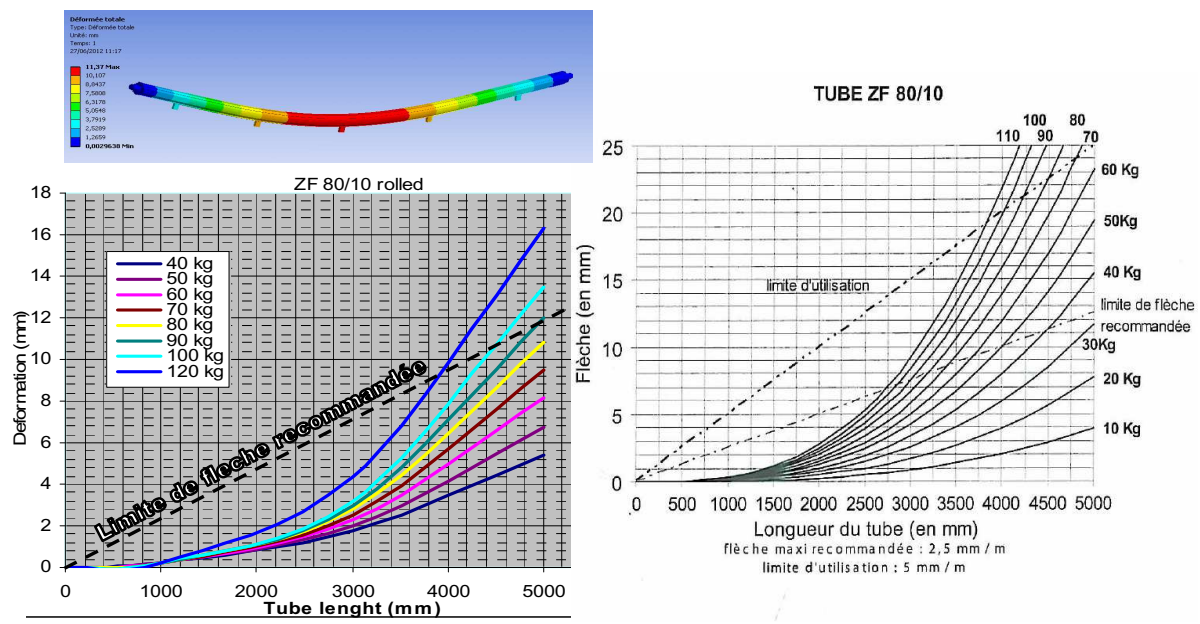

Fig. 4. Difference between new and old abacuses

\section{Conclusion}

This paper shows the first results of our methodology applied in a mid-sized firm, specialized in shutter components. According to the environment, our methodology allows a reduction of non value-added tasks such as documentation research and time loose when the installer needs expert advice when his case is over the permissive curves of the abacuses. This time saving allows the user and experts to devote more time to innovative design and saves time for the installer. In the short term perspective, the new abacuses will be implemented in the firm's standard catalogue for all installers. Additionally, an on line decision support system will be integrated on ZURFLUH-FELLER website, available to every installer along with the abacuses. As mid-term perspectives, other applications using the same method will be built in order to check their reliability and reassure the installer in his choice of component for his shutter assembly. 


\section{References}

1. Miles, B.L., Swift, K.G.: Working together. Manufacturing Breakthrough 4, 69-73 (1992)

2. Yeh, R.T.: Notes on concurrent engineering. IEEE Transation on Knowledge Data Engineering 4(5), 407-414 (1992)

3. Boudouh, T., Anghel, D.C., Garro, O.: Design iterations in a geographically distributed design process. In: ElMaraghy, H., ElMaraghy, W. (eds.) Advances in Design, vol. 4, pp. 377-386. Springer (January 2006) ISBN: 1-84628-004-4

4. Stark, J.: Product Lifecycle Management: 21st Century Paradigm for Product Realisation. Springer London Ltd., London (2004) ISBN: 978-1852338107

5. CIMdata Incorporated. PLM Market Growth in 2008 A Mid-Year Look in 2009Weathering the Storm'. White Paper (August 2009)

6. Lu, S.C.Y., Elmaraghy, W., Schuh, G., Wilhelm, R.: A scientific foundation of collaborative engineering. CIRP Annals - Manufacturing Technology 56(2), 605-634 (2007)

7. Baxter, D., Gao, J., Case, K., Harding, J., Young, B., Cochrane, S., Dani, S.: A framework to integrate design knowledge reuse and requirements management in engineering design. Robotics and Computer-Integrated Manufacturing 24(4), 585-593 (2008)

8. Hauschild, M., Jeswiet, J., Alting, L.: From LifeCycle Assessment to Sustainable Production: Status and Perspectives. CIRP Annals - Manufacturing Technology 54(2), 1-21 (2005)

9. Swift, K.G.: Process Selection: From Design to Manufacture, Butterworth Heinemann (2003)

10. Toussaint, L., Lebaal, N., Schlegel, D., Gomes, S.: Automatic Optimization of Air Conduct Design Using Experimental Data and Numerical Results. Int. J. Simul. Multidisci. Des. Optim. 4, 77-83 (2011)

11. Djiaz, C., Monticolo, D., Matta, N.: Capitalization of Knowledge from Projects. In: International Conference of Concurrent Engineering (CE), Antibes, France (2006)

12. Matta, N., Ribiere, M., Corby, O., Lewkowicz, M., Zaclad, M.: Project Memory in Design. In: Rajkumar, R. (ed.) Industrial Knowledge Management - A Micro Level Approach. Springer (2000)

13. Ermine, J.-L.: La Gestion des Connaissances, un levier stratégique pour les entreprises. IC'2000 Ingénierie des connaissances, Toulouse (2000)

14. Ermine, J.: La gestion de connaissances. Hermès Sciences publications (2002)

15. Serrafero, P.: Vers la mesure de la quantité de connaissance et de compétence industrielle: le modèle KnoVA. 1er colloque du Groupe de Gestion des Compétences et des Connaissances en Génie Industriel. Nantes, France (2002)

16. Ou, H., Wang, P., Lu, B., Long, H.: Finite element modelling and optimisation of netshape metal forming processes with uncertainties. Computers and Structures, 90-91, 1327 (2012)

17. Grundstein, M.: gameth ${ }^{\circledR}$ : un cadre directeur pour repérer les connaissances cruciales pour l'entreprise. Nogent-sur-Marne, MG Conseil: 29 (2007)

18. Boxberger, J., Lebouteiller, M., Schlegel, D., Lebaal, N., Gomes, S.: Vers une démarche d'ingénierie "hautement productive" des domaines projet-produit-process en contexte PME-PMI. 20ème Congrès Français de Mécanique, Besançon (2011) 